Please do not remove this page

RMIT

UNIVERSITY

\title{
A decision model for benchmarking knowledge management practices
}

Deng, Hepu

https://researchrepository.rmit.edu.au/esploro/outputs/9921862319001341/filesAndLinks?institution=61RMIT_INST\&index=null

Deng, H. (2006). A decision model for benchmarking knowledge management practices. International Conference on Computational Inteligence for Modelling Control and Automation and International Conference on Intelligent Agents Web Technologies and International Commerce, 233-233.

https://doi.org/10.1109/CIMCA.2006.3

Published Version: https://doi.org/10.1109/CIMCA.2006.3

Repository homepage: https://researchrepository.rmit.edu.au

(c) 2006 IEEE. Personal use of this material is permitted. However, permission to reprint/republish this material for advertising or promotional purposes or for creating new collective works for resale or redistribution to servers or lists, or to reuse any copyrighted component of this work in other works must be obtained from the IEEE.

Downloaded On 2023/04/26 23:25:28 +1000 


\title{
A Decision Model for Benchmarking Knowledge Management Practices
}

\author{
Hepu Deng \\ School of Business Information Technology \\ RMIT University \\ GPO Box 2476V, Melbourne, 3000, Victoria, Australia \\ Hepu.Deng@rmit.edu.au
}

\begin{abstract}
This paper presents a decision model for benchmarking and evaluating organizational knowledge management (KM) practices. Linguistic variables approximated by fuzzy numbers are used for adequately handling the subjectiveness and imprecision of the evaluation process. Pairwise comparison is adopted in the evaluation process for greatly reducing the cognitive burden of the decision maker. A fuzzy multicriteria analysis algorithm is developed for generating an overall ranking of all the organizations regarding their KM practices. As a result, the relative performance of organizations in managing their knowledge can be properly assessed, and effective decisions can be made for further improving their KM practices. An empirical study in evaluating the KM practices at Victorian local governments in Australia is presented for demonstrating the applicability of the proposed decision model in real situations.
\end{abstract}

\section{Introduction}

Knowledge management (KM) refers to the identification, creation, distributing, utilization, and maintenance of organizational knowledge for fulfilling organizational objectives $[1,2]$. Effectively managing organizational knowledge becomes increasingly important for organizations to gain competitive advantages nowadays. This is due to the increasingly competitive markets; the emergence of knowledge as the principal source of competitive advantage; a vast flood of information in both structured and unstructured formats; the continued pressures to align information flows and business processes; and the pressures of rapid technological change $[2,4]$.

To make full use of the potential of effective KM, organizations worldwide have adopted various strategies and policies in implementing innovative $\mathrm{KM}$ initiatives. Numerous successful stories have been reported, novel KM models have been developed [1, 3, 13]. There is however no much reported research in benchmarking and evaluating the effectiveness of organizational KM practices. In particular the appropriate methodology for carrying out this kind of study is not available for practitioners in real situations.

This paper formulates the problem of benchmarking and evaluating organizational $\mathrm{KM}$ practices as a multicriteria analysis (MA) problem and proposes a decision model for solving the problem in a straightforward manner. Linguistic variables approximated by fuzzy numbers are used for adequately modelling the subjectiveness and imprecision of the evaluation process. Pairwise comparison is used for effectively reducing the decision maker's (DM) cognitive burden in the evaluation process. A fuzzy MA algorithm is developed for generating an overall ranking of organizations regarding their KM practices, resulting in consistent and effective decisions being made.

In what follows, we first describe the problem of benchmarking and evaluating $\mathrm{KM}$ practices at Victorian local governments, followed by a discussion of the concepts of fuzzy set theory, linguistic variables, fuzzy extent analysis, and fuzzy similarity. We then present a decision model for solving this problem. Finally, we provide an empirical study to illustrate the applicability of the novel decision model proposed.

\section{Knowledge management practices in Victorian local governments}

Australia is a multi-cultural society of more than 20 million people living mainly around the coastline and in large cities. The six states and two territories have their own elected governments. There is a nationally 
elected government in Federal Parliament in Canberra. Local government in Australia is the responsibility of individual state governments. Since the 1990s, the trend has been away from prescriptive legislation in which what councils can and cannot do to the provision of enabling frameworks, within which councils have some degree of discretion in initiating their own policy directions. Following recent restructuring there are around 700 local authorities in Australia, most of them with small populations and some covering vast areas.

Local governments in Australia have a narrow range of functions. It does not take general responsibility for the provision of services. Although communities elect their own councilors, these and local mayors are essentially part-time figures. With the advent of new models of local government based on shared responsibility between a council and a professional city manager, the Mayor is no longer the Chief Executive Officer. Clearly in what is a much more business-like and indeed, entrepreneurial environment, those responsible for the administration and management of local government need access to the best information and knowledge available.

The need to respond to the challenges presented by organizational knowledge has resulted in wholesale structural and cultural changes in private sector organizations. Given the blurring of the once distinct boundaries between profit and not-for-profit operations the same need is now being felt in the public sector.

To be effective, any proposed response should avoid the temptations of silver bullet-type digital solutions, although a range of increasingly sophisticated information and communications technologies are available to assist in and enable the process of knowledge-based change. Within a KM architecture firmly aligned to organizational objectives, these can provide an electronic framework for capturing, codifying and distributing key information and knowledge throughout the organization.

Essentially, however, what is required is a response that promises to build the kind of capabilities likely to integrate, exploit and dynamically re-configure knowledge in order to deliver customer value. This will entail attention to those wider cultural issues identified as critical to knowledge-based change in the private sector, issues of staff collaboration, knowledgesharing and organizational learning. This is proved to be the case at Victorian local governments in Australia in which various policies and strategies have been adopted for facilitating the organizational knowledge sharing and improving the organizational learning.
To gain insights into the extent to which the KM practice has permeated the sphere local government in Australia, in particular to identify their relative status of managing their knowledge across their peers in Victorian local governments is therefore of great significance. Such an evaluation would offer a number of benefits. First it would indicate the extent to which the concept and practice of KM are a part of the mission and strategic planning of local authorities. Second, it might indicate the extent of any differences in perception between those of top management and the people at middle and lower levels in the organizational hierarchy. Third, it could help identify any developing trends whereby local governments are becoming knowledge-based organizations.

Four evaluation criteria, including the awareness of $\mathrm{KM}$ value $\left(C_{1}\right)$; the quality of $\mathrm{KM}\left(C_{2}\right)$, the degree of knowledge sharing $\left(C_{3}\right)$; and the organizational learning ability $\left(C_{4}\right)$, are used for the evaluation process. Against these evaluation criteria individual local Victorian governments are to be evaluated with respect to their relative performance in effective $\mathrm{KM}$.

The awareness of KM value $\left(C_{l}\right)$ refers to the recognition of an organization and its employees on the importance of $\mathrm{KM}$ and those innovative $\mathrm{KM}$ practices. This is determined by the perception of DMs with respect to the importance of $\mathrm{KM}$ in their organizational endeavors for excellence. The quality of KM practice $\left(C_{2}\right)$ refers to the effectiveness and efficiency of $\mathrm{KM}$ practices in an organization, including whether there is a loss of knowledge either through staff defections or retirement or simply poor resource management.

The degree of knowledge sharing $\left(C_{3}\right)$ is concerned about the ability of an organization to share knowledge and intellectual resources. A major means by which knowledge can be leveraged within organizations is through the use of mechanisms for knowledge exchange. This involves in various mechanisms such as knowledge sharing and the re-use of knowledge and learning in practice. An organization with a high level of knowledge sharing would actually decrease the possibility of people creating and recreating the same knowledge in the organization, a phenomenon commonly referred to reinvention of the wheel.

The organizational learning ability $\left(C_{4}\right)$ is of critical importance for effective organizational KM, something that applies both to organizations and to the people within them. Learning seems to be a highly prized characteristic within local government in Australia.

Subjective assessments are made to evaluate the relative importance of the evaluation criteria and the performance of local governments with respect to each 
criterion. These assessments are then aggregated so that an overall performance index for each local government can be produced.

\section{Preliminary concepts}

A fuzzy number is a convex fuzzy set [15], characterized by a given interval of real numbers, each with a grade of membership between 0 and 1. Its membership function $\mu_{A}(x)$ is piecewise continuous, and satisfies the conditions including (a) $\mu_{A}(x)=0$ for each $x \in\left(-\infty, a_{1}\right] \cup\left[a_{4},+\infty\right)$, (b) $\mu_{A}(x)$ is non-decreasing on $\left[a_{1}, a_{2}\right]$ and non-increasing on $\left[a_{3}, a_{4}\right]$, and $\mu_{A}(x)=$ 1 for each $x \in\left[a_{2}, a_{3}\right]$ where $a_{1} \leq a_{2} \leq a_{3} \leq a_{4}$ are real numbers in the real line $R$.

Triangular fuzzy numbers are a special class of fuzzy number [10], defined by three real numbers, often expressed as $\left(a_{1}, a_{2}, a_{3}\right)$. Their membership functions $\mu_{A}(x)$ are usually described as

$$
\mu_{A}(x)= \begin{cases}\frac{x-a_{1}}{a_{2}-a_{1}}, & a_{1} \leq x \leq a_{2}, \\ \frac{a_{3}-x}{a_{3}-a_{2}}, & a_{2} \leq x \leq a_{3}, \\ 0, & \text { otherwise. }\end{cases}
$$

where $a_{1} \leq a_{2} \leq a_{3}$ are real numbers. In practical situations, $a_{2}$ is usually used to represent the most possible value of fuzzy number $A$, and $a_{1}$ and $a_{3}$ are used to respectively indicate the lower and upper bounds of fuzzy number $A$ that are often used to illustrate the fuzziness of the data evaluated $[9,14]$.

Linguistic variables have been found intuitively easy to use in expressing the subjectiveness and imprecision of the DM's assessments [6, 14]. To facilitate the making of subjective assessments in the evaluation process, linguistic variables approximated by fuzzy numbers and defined as in Table 1 are used.

Table 1 Linguistic variables for making subjective pairwise assessments

\begin{tabular}{l|c}
\hline Linguistic variables & Fuzzy numbers \\
\hline Very Poor (VP) & $\overline{1}=(1,1,3)$ \\
Poor (P) & $\overline{3}=(1,3,5)$ \\
Fair (F) & $\overline{5}=(3,5,7)$ \\
Good (G) & $\overline{7}=(5,7,9)$ \\
Very Good (VG) & $\overline{9}=(7,9,9)$ \\
\hline
\end{tabular}

Fuzzy synthetic extent analysis [5] is widely used in decision analysis when fuzzy data are present. Chang [5] applies this concept for extending the fuzzy analytic hierarchy process [12]. Zhu et al. [16] use this concept for formulating a petroleum-prospecting problem in a fuzzy environment. These empirical studies demonstrate the effectiveness of this concept in decision analysis due to its simplicity in concept and its ease of use in practical situations.

Assume that $X=\left\{x_{1}, x_{2}, \ldots, x_{n}\right\}$ is an object set, and $U=\left\{u_{1}, u_{2}, \ldots, u_{m}\right\}$ is a goal set. By applying the method of fuzzy extent analysis with respect to each object for each goal respectively [5], $m$ extent analysis values for each object can be obtained, given as $\mu_{i}^{1}, \mu_{i}^{2}, \ldots, \mu_{i}^{m}$ where $\mu_{i}^{j}(i=1,2, \ldots, n ; j=1,2, \ldots, m)$ are fuzzy numbers representing the performance of the object $x_{i}$ with regard to goal $u_{j}$.

Aggregating these extent analysis values for each object across all goals using fuzzy synthetic extent analysis [5], the overall performance of the object across all goals can be calculated by

$$
S_{i}=\frac{\sum_{j=1}^{m} \mu_{i}^{j}}{\sum_{i=1}^{n} \sum_{j=1}^{m} \mu_{i}^{j}}, i=1,2, \ldots, n .
$$

where $S_{i}(i=1,2, \ldots, n)$ represents the fuzzy performance of object $x_{i}$ across all goals.

Numerous measures of similarity between fuzzy numbers have been proposed [6]. These measures are used to reflect the relationships between fuzzy numbers from various dimensions. Some of these measures have been used in system analysis and linguistic approximation for solving practical problems.

A distance-based measure of two fuzzy numbers is a way to describe the closeness between two fuzzy numbers $[6,10]$. It is often used to determine the degree of similarity between two fuzzy numbers. Let $A_{i}$ $=\left(a_{i}, b_{i}, c_{i}\right)$ and $A_{j}=\left(a_{j}, b_{j}, c_{j}\right)$ be two triangular fuzzy numbers, the fuzzy similarity between these two fuzzy numbers can be defined as

$$
d\left(A_{i}, A_{j}\right)=\sqrt{\frac{1}{3}\left(\left(a_{i}-a_{j}\right)^{2}+\left(b_{i}-b_{j}\right)^{2}+\left(c_{i}-c_{j}\right)^{2}\right)}
$$

\section{The decision model}

MA is widely used for ranking alternatives with respect to multiple criteria $[6,8]$. Evaluating organisational KM practices obviously involves multiple criteria with subjective assessments. An overall ranking of local governments are required regarding the relative performance of their $\mathrm{KM}$ practices. In line with the multi-dimensional nature of the evaluation process, MA provides an effective framework for solving the problem due to its simplicity and comprehensibility in concept and its capability to handle multiple criteria. However, MA approaches are generally inadequate for dealing with 
situations in which imprecision and subjectiveness are present $[6,17]$.

The application of fuzzy set theory in MA allows the DM to effectively formulate the decision problem in a fuzzy environment where the information available is subjective and imprecise [5, 6, 17]. The subjectiveness and imprecision of the decision process can be better modelled by fuzzy numbers with the use of linguistic variables.

To make full use of individual merits of existing MA methodologies, fuzzy set theory and linguistic variables, this section presents a decision model for evaluating and benchmarking the relative performance of KM practices at Victorian local governments. The decision model involves in (a) applying pairwise comparison for assessing the relative importance of the evaluation criteria and the performance ratings of individual alternatives with respect to each criterion, (b) using linguistic variables defined as in Table 1 to represent the subjective assessments, (c) calculating the criteria weighting and performance rating of alternatives using fuzzy synthetic analysis, (d) aggregating the fuzzy criteria weightings and performance ratings for producing a weighted fuzzy performance matrix using fuzzy arithmetic, and (e) calculating an overall performance index for each alternative across all criteria in line with the concepts of fuzzy maximum/minimum and fuzzy similarity.

The general evaluation problem usually consists of a number of alternatives $A_{i}(i=1,2, \ldots, n)$ to be evaluated against a set of selection criteria $C_{j}(j=1,2$, $\ldots, m)$. Subjective assessments are often required for determining the performance of each alternative $A_{i}$ with respect to each criterion, denoted as $x_{i j}(i=1,2$, $\ldots, n ; j=1,2, \ldots, m)$, and the relative importance of the each criterion, represented as $w_{j}(j=1,2, \ldots, m)$, with respect to the overall objective of the problem.

The decision-making procedure starts at determining the criteria weightings and alternative performance ratings with respect to each criterion. By using the linguistic variables defined as in Table 1, a fuzzy reciprocal judgement matrix for criteria importance or for the alternative performance ratings with respect to each criterion can be determined as

$$
\begin{gathered}
\bar{A}=\left[\begin{array}{cccc}
- & - & & - \\
a_{11} & a_{12} & \ldots & a_{1 k} \\
- & - & & - \\
a_{21} & a_{22} & \ldots & a_{2 k} \\
\ldots & \ldots & \ldots & \ldots \\
- & - & \ldots & - \\
a_{k 1} & a_{k 2} & \ldots & a_{k k}
\end{array}\right] \\
\text { Where } a_{i k}=\left\{\begin{array}{lll}
V P, P, F, G, V G, & l<s, \\
1, & l=s, & l, s=1,2, \ldots, k, k=m \text { or } n . \\
1 / a_{k}, & l>s .
\end{array}\right.
\end{gathered}
$$

By applying (2) on (3), the corresponding criteria weightings or the alternative performance ratings with respect to criterion $C_{j}$ can then be determined respectively, resulting in the decision matrix and the weight vector respectively determined as

$$
\begin{aligned}
X & =\left[\begin{array}{cccc}
x_{11} & x_{12} & \ldots & x_{1 m} \\
x_{21} & x_{22} & \ldots & x_{2 m} \\
\ldots & \ldots & \ldots & \ldots \\
x_{n 1} & x_{n 2} & \ldots & x_{n m}
\end{array}\right] \\
W & =\left(w_{1}, w_{2}, \ldots, w_{m}\right)
\end{aligned}
$$

where $x_{i j}$ represents the fuzzy performance of alternative $A_{i}(i=1,2, \ldots, n)$ with respect to criterion $C_{j}$ and $w_{j}$ is the fuzzy weight of the criterion $C_{j}(j=1$, $2, \ldots, m)$.

With the decision matrix and the weighting vector as above, a fuzzy performance matrix (7) representing the weighted performance of alternatives with respect to each criterion can be determined by multiplying the weighting vector in (6) by the decision matrix in (5).

$$
Z=\left[\begin{array}{cccc}
w_{1} x_{11} & w_{2} x_{12} & \ldots & w_{m} x_{1 m} \\
w_{1} x_{21} & w_{2} x_{22} & \ldots & w_{m} x_{2 m} \\
\ldots & \ldots & \ldots & \ldots \\
w_{1} x_{n 1} & w_{2} x_{n 2} & \ldots & w_{m} x_{n m}
\end{array}\right]
$$

To avoid the complex and unreliable process of comparing fuzzy utilities [6], the concepts of fuzzy maximum and fuzzy minimum are introduced for determining the relative performance of all the alternatives with respect to each criterion represented based on the concept of fuzzy similarity. As a result, a fuzzy maximum $\left(M_{\max }^{j}\right)$ and a fuzzy minimum $\left(M_{\min }^{j}\right)$ are defined for each given fuzzy vector $\left(w_{j} x_{1 j}, w_{j} x_{2 j}, \ldots, w_{j} x_{n j}\right)(j=1,2, \ldots, m)$ in (7) representing the fuzzy performance of all alternative $A_{i}$ with respect to each criterion $C_{j}$. Their membership functions are determined respectively as

$$
u_{M_{\max }^{j}}(x)= \begin{cases}\frac{x-x_{\min }^{j}}{x_{\max }^{j}-x_{\min }^{j}}, & x_{\min }^{j} \leq x \leq x_{\max }^{j}, \\ 0, & \text { otherwise }\end{cases}
$$

$$
u_{M_{\min }^{j}}(x)=\left\{\begin{array}{ll}
\frac{x_{\max }^{j}-x}{x_{\max }^{j}-x_{\min }^{j}}, & x_{\min }^{j} \leq x \leq x_{\max }^{j}, \\
0, & \text { otherwise }
\end{array},\right.
$$

where

$$
\begin{aligned}
x_{\max }^{j} & =\sup \left(\operatorname{supp} \bigcup_{i=1}^{n}\left(w_{j} x_{i j}\right)\right), \\
x_{\min }^{j} & =\inf \left(\operatorname{supp} \bigcup_{i=1}^{n}\left(w_{j} x_{i j}\right)\right) .
\end{aligned}
$$


Based on the concept of fuzzy similarity, the similarity between each alternative and fuzzy maximum can be calculated as follows:

$$
S_{i}^{+}=\sum_{j=1}^{m} d_{i j}\left(x_{i j} w_{j}, M_{\max }^{j}\right)
$$

By the same token, the similarity between each alternative and the fuzzy minimum is calculated as:

$$
s_{i}^{-}=\sum_{j=1}^{m} d_{i j}\left(x_{i j} w_{j}, \quad M_{\min }^{j}\right)
$$

A preferred alternative is to be as close to the fuzzy maximum as possible, and as far away from the fuzzy minimum as possible $[6,8]$. Therefore, an overall performance index for each alternative $A_{i}$ across all criteria can be calculated by

$$
P_{i}=\frac{s_{i}^{-}}{s_{i}^{+}+s_{i}^{-}}, \quad i=1,2, \ldots, n .
$$

The larger the performance index, the more preferred the alternative.

Summarizing the discussion as above, the decision model for determining the overall ranking of all alternatives across all criteria can be described algorithmically as follows:

Step 1. Formulate the decision problem as a MA problem with the identification of alternatives and evaluation criteria

Step 2. Assess alternative performance ratings with respect to each criterion using pairwise comparison with the linguistic variables defined as in Table 1, resulting in the fuzzy reciprocal judgment matrix described as in (3).

Step 3. Apply fuzzy synthetic extent analysis on the fuzzy reciprocal judgment matrix from Step 3, resulting in the determination of the fuzzy decision matrix for all alternatives across all criteria as in (5).

Step 4. Assess the criteria weightings using pairwise comparison with the linguistic variables defined as in Table 1, resulting in the fuzzy reciprocal judgment matrix described as in (3).

Step 5. Apply fuzzy synthetic extent analysis on the fuzzy reciprocal judgment matrix from Step 4, resulting in the determination of the fuzzy criteria weights as in (6).

Step 6. Calculate the weighted fuzzy performance matrix by multiplying the fuzzy decision matrix in (5) by the fuzzy weightings in (6).

Step 7. Determine the fuzzy maximum and fuzzy minimum by (7) and (8).
Step 8. Calculate the similarity between each alternative and the fuzzy maximum or fuzzy minimum by (9) and (10).

Step 9. Determine the rankings of all alternatives by calculating their overall index values by (11).

\section{An Empirical Study}

This section presents an empirical study to demonstrate the applicability of the decision model for benchmarking and evaluating the KM practices. As discussed in Section 2, four evaluation criteria, the awareness of $\mathrm{KM}$ value $\left(C_{1}\right)$; the quality of $\mathrm{KM}\left(C_{2}\right)$, the degree of knowledge sharing $\left(C_{3}\right)$; and the organizational learning ability $\left(C_{4}\right)$, are considered for evaluating and benchmarking three local governments $\left(A_{1}, A_{2}, A_{3}\right)$ with respect to their KM practices.

Using the linguistic variables defined as in Table 1, the performance ratings of three local governments with respect to the four criteria based on pairwise comparison can be determined, resulting in the four fuzzy reciprocal judgment matrix as follows:

$$
\begin{aligned}
& \left.\begin{array}{rlll} 
& A_{1} & A_{2} & A_{3} \\
A_{1} & A_{1} \\
A_{2} & {\left[\begin{array}{c}
\overline{1} \\
A_{3}
\end{array}\right.} & \overline{3} & \overline{9} \\
\overline{3} & \overline{1} & \overline{5} \\
\overline{9} & \overline{5} & \overline{1}
\end{array}\right]
\end{aligned}
$$

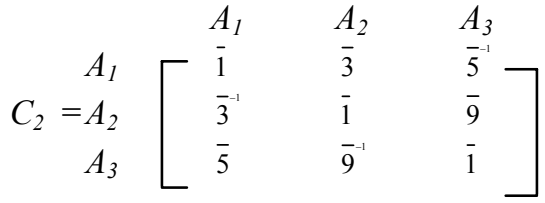

$$
\begin{aligned}
& \left.\begin{array}{rccc} 
& A_{1} & A_{2} & A_{3} \\
A_{1} & {\left[\begin{array}{c}
\overline{1} \\
C_{3}=
\end{array} A_{2}\right.} \\
A_{3} & \overline{9} & \overline{7} \\
\overline{9} & \overline{1} & \overline{3} \\
\overline{7} & \overline{3} & \overline{1}
\end{array}\right]
\end{aligned}
$$

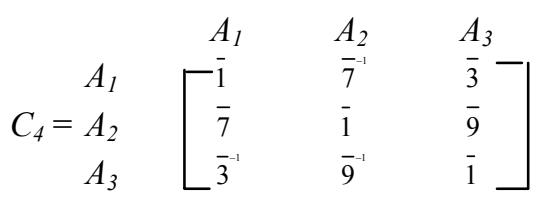

Using fuzzy synthetic extent analysis, the fuzzy decision matrix for the evaluation problem can then be determined based on fuzzy arithmetic [11] as follows:

$X=\left[\begin{array}{llll}(0.27,0.631 .32) & (0.060 .120 .58) & (0.17,0.360 .74) & (0.060 .180 .50) \\ (0.13,0.31,0.76) & (0.240 .501 .04) & (0.23,0.460 .91) & (0.37,0.75,1.40) \\ (0.04,0.060 .24) & (0.120 .300 .70) & (0.060 .180 .50) & (0.04,0.060 .25)\end{array}\right]$

To determine the relative importance of the evaluation criteria, fuzzy pairwise comparison process is used, resulting in a fuzzy reciprocal judgement matrix $(W)$ as follows:

$$
\begin{array}{llll}
C_{1} & C_{2} & C_{3} & C_{4}
\end{array}
$$




$$
W=\begin{aligned}
& C_{1} \\
& C_{2} \\
& C_{3} \\
& C_{4}
\end{aligned}\left[\begin{array}{ccccc}
\overline{1} & \overline{3} & \overline{7} & \overline{5} \\
\overline{3} & \overline{1} & \overline{9} & \overline{3} \\
\overline{7} & \overline{9} & \overline{1} & \overline{3} \\
\overline{5}^{-1} & \overline{3} & \overline{3} & \overline{1}
\end{array}\right]
$$

Similarly, the weighting vector can be determined by (3) to (5) using fuzzy extent analysis as follows:

$w_{1}=(0.17,0.45,1.05), \quad w_{2}=(0.16,0.38,0.87)$,

$w_{3}=(0.02,0.04,0.19), \quad w_{4}=(0.04,0.13,0.41)$.

Following the procedures described as above, an overall performance index value for each local government involved across the four evaluation criteria can be determined. Table 2 shows the results.

Table 2 Performance index values and the corresponding rankings of the local governments

\begin{tabular}{ccc}
\hline Alternatives & Performance index & Ranking \\
\hline$A_{1}$ & 0.51 & 1 \\
$A_{2}$ & 0.37 & 2 \\
$A_{3}$ & 0.12 & 3 \\
\hline
\end{tabular}

The decision model clearly has its advantages, including (a) better modeling of the subjectiveness and imprecision of the decision process and (b) cognitively less demanding on the DM. Real experience in applying the decision model for benchmarking and evaluating $\mathrm{KM}$ practices in Victorian local governments has reinforced these findings.

\section{Conclusion}

Benchmarking and evaluating the $\mathrm{KM}$ practices of organizations is of great significance in real world settings. This paper presents a novel decision model capable of adequately evaluating the KM practices in Victorian local governments in Australia. The subjectiveness and imprecision of the human decisionmaking process are properly handled using linguistic variables represented by fuzzy numbers. Pairwise comparison is used in the evaluation process for greatly reducing the cognitive burden on the DM. As a result the proposed decision model can help organisations identify their relative status in their KM practices and facilitates the pursuit of innovative KM policies and strategies for better performance.

\section{References}

[1] M. Alavi, Managing Organizational knowledge: framing the domains of IT management, Cincinatti, Pinnaflex, 2000.

[2] M. Alavi, "Knowledge Management Systems: Issues, Challenges and Benefits", Proceedings of the
Hawaii International Conference on Systems Sciences, January, 1999.

[3] M. Alavi and D. E. Leidner, "Knowledge Management and Knowledge Management Systems: Conceptual Frameworks and Research Issues", MIS Quarterly 25, 2001, pp. 107-32.

[4] S. A. Carlsson, E. I. Sawy, O. A., et al., "Gaining Competitive Advantage through Shared Knowledge Creation: in Search of A New Design Theory for Strategic Information Systems", Proceedings of the Fourth European Conference on Information Systems, Lisbon, 1996.

[5] D.Y. Chang, "Applications of the Extent Analysis Method on Fuzzy AHP", European Journal of Operational Research, vol. 95, 1996, pp. 649-655.

[6] S.J. Chen, and C.L. Hwang, Fuzzy multiple attribute decision making: methods and applications, Springer-Verlag, New York, 1992.

[7] C.H. Cheng, "Evaluating Naval Tactical Missile Systems by Fuzzy AHP based on the Grade Value of Membership Function", European Journal of Operational Research, vol. 96, 1996, pp. 343-350.

[8] C.L. Hwang, and K.S. Yoon, Multiple attribute decision making: methods and applications, SpringerVerlag, Berlin, 1981.

[9] C.H. Juang, and D.H. Lee, "A Fuzzy Scale for Mmeasuring Criteria Weights in Hierarchical Structures", Proceedings of IFES, 1991, pp. 415-421. [10] A. Kaufmann, and M.M. Gupta, Introduction to Fuzzy Arithmetic Theory and Application, Van Nostrand Reinhold, New York, 1985.

[11] G. Lawton, "Knowledge Management: Ready for Prime Time?", Computer, vol. 34, 2001, pp. 12-14.

[12] T.L. Saaty, Decision Making for Leaders, third edition, RWS Publications, New York, 1995.

[13] K. E. Sveiby, The New Organizational Wealth: Managing and Measuring Knowledge-based Assets, San Francisco, Berrett-Koehler Publishers, 1997.

[14] C.H. Yeh, H. Deng, and H. Pan, "Multi-Criteria Analysis for Dredger Dispatching under Uncertainty", Journal of the Operational Research Society, vol. 50, 1999, pp. 35-43.

[15] L.A. Zadeh, "Fuzzy Sets", Information and Control, vol. 8, 1965, pp. 338 - 353.

[16] K.J. Zhu, Y. Jing, and D. Y. Chang, "A Discussion on Extent Analysis Method and Applications of Fuzzy AHP", European Journal of Operational Research, vol. 116, pp. 1999, pp. 450456.

[17] H.-J. Zimmermann, Fuzzy Set Theory and Its Applications, Kluwer Academic Publishers, Boston, 1996. 